\title{
The impact of a breastfeeding promotion program at a health center
}

\author{
Adolfo P. B. Lana1, Joel A. Lamounier², Cibele C. César ${ }^{3}$
}

\begin{abstract}
Objectives: To determine the impact on breastfeeding sustained beyond two months of the "Seventeen Steps" breastfeeding maintenance program consisting of seventeen strategies used to promote, support and protect breastfeeding and implemented for ten months at a medical center.

Methods: Non randomized clinical trial, involving 147 children born between 01/01/99 and 31/12/2001, who had attended their first medical appointment before two months; 67 children who had passed through the traditional program were studied retrospectively and 80 that had the "17 steps" applied to them were studied prospectively. Maximum follow up period was ten months. The program's impact on breastfeeding was evaluated through survival analysis techniques. The survival curves were described by the Kaplan Meier method and compared with the log-rank test. The Cox regression model was used for covariate adjustment. The initial group comparison was done through the $t$, Kruskal-Wallis and chisquared tests. The significance level adopted was $5 \%$.

Results: Adjusting for mother-child covariates, a significant difference was observed in breastfeeding duration between the two groups $(p=0.047)$. The relative risk of interrupting breastfeeding for the " 17 steps" group was $R R=0.54$ $(95 \mathrm{CI}=0.30-0.99)$, indicating that there was an $85 \%$ greater risk that children on the traditional program would be weaned before completing a year than there was that children on the "17 steps" program would be.
\end{abstract}

Conclusion: The program had a positive impact on the duration of breastfeeding from two to twelve months of age.

J Pediatr (Rio J). 2004;80(3):235-40: Intervention, promotion, evaluation, program and breastfeeding.

\section{Introduction}

The nutritional, immunological and physiological properties of human milk, the psychoaffective factors resulting from mother-child interaction during breastfeeding and the economic factor can all be translated into benefits for children, mothers, families, society and the State itself. ${ }^{1,2}$

Brazilian data reveals that $96 \%$ of women begin breastfeeding, just $11 \%$ exclusively breastfeed until between 4 and 6 months, $41 \%$ prolong maternal breastfeeding until 1 year and $14 \%$ for two years, ${ }^{3}$ rates below those recommended by the World Health Organization, which are: exclusive breastfeeding until 6 months and supplemented breastfeeding until at least 2 years of age. ${ }^{4}$

1. MSc, Universidade Federal de Minas Gerais (UFMG), Belo Horizonte, $M G$, Brazil.

2. Associate professor, Department of Pediatrics, School of Medicine, UFMG, Belo Horizonte, MG, Brazil.

3. Associate professor, Department of Statistics, School of Economics, UFMG, Belo Horizonte, MG, Brazil.

Manuscript received May 19 2003, accepted for publication Feb 112004.
The lack of preparation of health personnel is an added factor. False beliefs about the practice of breastfeeding are found among them too. 5,6

Breastfeeding promotion programs that include capacitating health care teams have a great impact on these professionals' practices, resulting in longer duration breastfeeding in the communities they serve. 7,8

This study evaluates the impact of a breastfeeding promotion program consisting of " 17 steps" implemented at a health center on the duration of breastfeeding from two months onwards, with a cut off at 12 months.

\section{Methods}

The sample consisted of 147 children born between $1 / 1 / 99$ and $31 / 12 / 01$ whose mothers had spontaneously chosen the São Francisco Health Center, a basic health unit located in the Pampulha Health District, North Belo Horizonte, before they were two months old and who were still being breastfed at two months. They were all residents of the area 
served and influenced by the health center, which is an area characterized by low incomes.

There were no losses from the sample, since none of the mothers refused to participate, or were suffering from diseases or conditions that could contra-indicate maternal breastfeeding.

This is a non-randomized clinical trial; a quasiexperimental study. ${ }^{9}$ Group 1 , studied retrospectively, was made up of all children that had had their first childcare appointment before two months of age, were still breastfeeding at two months and had undergone traditional interventions ( 67 children born between 1/1/99 and $31 / 8 / 00)$. A second group, meeting the same breastfeeding criteria, were put on the " 17 steps" program and studied prospectively ( 80 children born between $1 / 12 / 00$ and $31 / 12 / 01$ - Group 2). The program was implemented between $01 / 09 / 00$ and $31 / 11 / 00$. Children in group 1 who were still being breastfed when the program was fully implemented ended up benefiting from it during part of their follow-up periods.

The traditional program consisted of the routine procedures previously employed at the health center: individual counseling for mothers from a pediatrician, weekly meetings with expectant mothers lasting around an hour covering prenatal themes and family counseling with no particular emphasis on breastfeeding.

A pediatrician capacitated health professionals by means of lectures and observation-based constructive criticism of breastfeeding counseling, both in terms of clinical handling and in terms of listening skills and the ability to bolster maternal self-confidence. The pediatrician's lecture also brought them up to speed on the seventeen breastfeeding promotion, support and protection strategies and the reasoning behind each of them (Table 1 ).

The following definitions were adopted for the purposes of the study:

Exclusive Breastfeeding (EB): the child only receives milk from its mother or wet nurse, or extracted breastmilk and no other liquids or solids with the exception of drops, vitamin extracts, mineral supplements or medicines. ${ }^{21}$

Predominant Breastfeeding (PB): the child's predominant source of nutrition is human milk. However, water and water-based drinks can be given (sugared or flavored water, infusions, teas, etc.), fruit juices, oral rehydration saline solutions, (ORS), vitamins, minerals and medicines in the form of drops or syrups. With the exception of fruit juices and sugared water, no liquids are permitted that are foodbased. 21

Supplemented Breastfeeding (SB): human milk is still one of the child's sources of nutrition, but other solid, semi solid and liquid foods, including non-human milk, are also given. ${ }^{21}$

Breastfeeding (BF): the child receives human milk, direct from the breast or expressed.

Weaning: the process by which breast milk is completely removed from the child's diet.
Sample size was calculated based on the following parameters: breastfeeding prevalence of $41 \%$ at 12 months, ${ }^{3}$ target prevalence of $65 \%$ at 12 months, probability of type 1 error $(\alpha)$ of 0.05 , test power (1- $\beta)$ of 0.80 , test directed towards increased impact. According to these criteria sample size was estimated at 71 children for each of the two groups.

Because of the inclusion criteria adopted, the final sample was made up of 67 children in the control group and 80 children in the treatment group. Although it was not possible to recruit the full number of children into the control group, the study power was not compromised because additional children were recruited into the treatment group.

A questionnaire was filled in on behalf of the mothers, exclusively by the researcher responsible, immediately before the childcare consultation. It covered a number of variables that allow the similarity between the two groups in terms of factors that could influence breastfeeding duration to be demonstrated (Table 2).

Measures aimed at fulfilling the "17 steps" were adopted throughout the different physical areas of the health center and involved many different types of employee, all exposed to the program. In the meeting room, expectant mothers and nursing mothers groups were run by a nursing auxiliary. Members shared fears, doubts and anxieties about maternity and breastfeeding, swapped experiences and received guidance. Prenatal consultations were set for Tuesdays and control checkups for breastfed children on Wednesdays. Women waiting for appointments with the obstetrician or pediatrician attended the groups. In the obstetrician's surgery expectant mothers were sensitized to breastfeeding and given printed material to be shared with pregnant or breastfeeding family members and friends. During the Guthrie test session a nursing auxiliary collected information on how breastfeeding was progressing, giving the mother positive reinforcement and, on completion of the test, referring her on to the pediatrician. In the pediatrician's surgery the condition of mother, baby and breastfeeding were assessed. Depending on this assessment the mother-baby pair were requested to return the next day or up to a maximum of a month later. The mothers were informed that the child could be seen even without an appointment and were given printed material, different on each occasion, to be read with friends and family. At reception and at the walk-in center breastfeeding children were always seen by a pediatrician even when there were no appointments available. At the pharmacy breastfeeding mothers with prescriptions for the combined pill were referred to the pediatrician for counseling.

Data was input on Epi-Info. 22 The following tests were used to compare groups: chi-square for categorical covariables, the Student $t$ test for means, the Kruskal Wallis test for medians; the Kaplan-Méier curve for survival analysis, taking weaning as the event under study, the logrank test to compare survival curves and Cox regression to adjust for mother and child characteristics. The cut-off for statistical significance was set at $5 \%(p<0.05)$. 
Table 1 - Seventeen breastfeeding promotion, support and protection strategies at the health center

\begin{tabular}{|c|c|c|}
\hline Step & Strategy & Reasoning \\
\hline 1 & Have written guidelines. & Guidelines may be the most important aspect of a program. ${ }^{10}$ \\
\hline 2 & $\begin{array}{l}\text { Sensitize, train and capacitate } \\
\text { the whole team of health professionals. }\end{array}$ & $\begin{array}{l}\text { Health professionals are generally not well prepared } \\
\text { for stimulating breastfeeding at health centers. } 5,6\end{array}$ \\
\hline 3 & $\begin{array}{l}\text { Provide information to pregnant women } \\
\text { and breastfeeding mothers and provide } \\
\text { written material to grandmother and fathers. }\end{array}$ & $\begin{array}{l}\text { The father and the grandmothers can interfere in } \\
\text { a negative manner,but they also can get benefits from the guidance } \\
\text { by playing a relevant role. }{ }^{11,12}\end{array}$ \\
\hline 4 & $\begin{array}{l}\text { Schedule appointments for the pregnant women } \\
\text { some days before the delivery and approach } \\
\text { the steps of the Baby Friendly Hospital. }\end{array}$ & The 10 steps widely promote breastfeeding. 8,13 \\
\hline 5 & Assess breastfeeding on the fifth day. & Early correction of breastfeeding problems must be performed. ${ }^{14}$ \\
\hline 6 & $\begin{array}{l}\text { See the breastfed infant even if the medical visit } \\
\text { has not been scheduled. }\end{array}$ & Any breastfeeding problem must be considered an emergency. ${ }^{14}$ \\
\hline 7 & $\begin{array}{l}\text { Schedule medical visits at least once } \\
\text { a month up to the } 6 \text { th month and at least } \\
\text { once every } 2 \text { months up to the } 24 \text { th month. }\end{array}$ & $\begin{array}{l}\text { Often the mother must receive the necessary motivation } \\
\text { to keep on breastfeeding. }{ }^{14}\end{array}$ \\
\hline 8 & $\begin{array}{l}\text { Comply with the Brazilian Regulation of Trading } \\
\text { of Food for Infants and Young Children, Pacifiers, } \\
\text { and Feeding Bottles. }\end{array}$ & $\begin{array}{l}\text { Mass marketing of these products reduces } \\
\text { the duration of breastfeeding. }{ }^{4}\end{array}$ \\
\hline 9 & $\begin{array}{l}\text { Advise about contraceptive methods appropriate } \\
\text { for the breastfeeding period. }\end{array}$ & $\begin{array}{l}\text { Postnatal family planning must benefit intergeneration } \\
\text { without interfering with breastfeeding. }{ }^{14}\end{array}$ \\
\hline 10 & $\begin{array}{l}\text { Provide information about working womens' rights } \\
\text { and how to keep on breastffeding } \\
\text { even after going back to work. }\end{array}$ & $\begin{array}{l}\text { Womens' return to work is one of the four main causes } \\
\text { of the low prevalence of breastfeeding. }{ }^{4}\end{array}$ \\
\hline 11 & $\begin{array}{l}\text { Recommend exclusive breastfeeding } \\
\text { up to } 6 \text { months and supplemented breastfeeding } \\
\text { up to } 2 \text { years. }\end{array}$ & $\begin{array}{l}\text { Most mothers believe that breastfeeding must be interrupted } \\
\text { after } 6 \text { months; they do not know that they should breastfeed } \\
\text { up to } 2 \text { years at least. } 3,14\end{array}$ \\
\hline 12 & Promote meetings for pregnant women. & Prenatal training increases breastfeeding rates. ${ }^{14-18}$ \\
\hline 13 & Promote meetings of breastfeeding mothers. & Postnatal appropriate guidance produces positive results. ${ }^{17}$ \\
\hline 14 & $\begin{array}{l}\text { Promote meetings for pregnant women } \\
\text { and breastfeeding mothers. }\end{array}$ & $\begin{array}{l}\text { With the purpose of providing the pregnant women } \\
\text { with the opportunity to take advantage of the } \\
\text { breastfeeding mothers' experience, observe breastfeeding technique, } \\
\text { milking and management of maternal milk in cups. }\end{array}$ \\
\hline 15 & Create groups of mothers who provide advice. & $\begin{array}{l}\text { The combination of community support plus } \\
\text { formal health service benefits breastfeeding. } 20\end{array}$ \\
\hline 16 & Pay complimment to the breastfeeding mother. & $\begin{array}{l}\text { The acknowledgement of the mother's correct behavior and } \\
\text { the complimment of the correct practice benefit breastfeeding. }{ }^{18}\end{array}$ \\
\hline 17 & $\begin{array}{l}\text { Grant awards to the health centers } \\
\text { that acchieve good breastfeeding rates. }\end{array}$ & It is a positive reinforcement for health professionals. \\
\hline
\end{tabular}

The project was submitted to and approved by the UFMG Medical Faculty Committee for Ethics in Research, hearing $111 / 02$ on $30 / 7 / 02$ and mothers' consent forms, the researcher's undertaking and the head of the institution's undertaking were all duly signed. This research is in accordance with Health Ministry resolution 196/96.

\section{Results}

Table 2 contains descriptions of the variables analyzed by program followed. The values represent mean \pm standard deviation for numerical variables. Categorical variables are represented in terms of absolute frequency with percentage frequency in parentheses. Analysis of this table shows that the "17 steps" and traditional groups are similar in terms of the characteristics analyzed, with the exception of duration of pregnancy, which returned a p-value of 0.021 . More careful study revealed that this statistical significance was the result of a single discrepancy (a 27-week pregnancy) in the " 17 steps" group. The scale of its influence was the result of the low level of variability observed for this variable (coefficient of variation $=4.68 \%$ ). Summing up, we can consider the groups to be equivalent in terms of the covariables analyzed.

Observing the Kaplan-Meier curves for the two groups (Figure 1) it will be noted that the "17 steps" group 
Table 2 - Description of the variables in the traditional group or in the 17 steps group at the health center from January 1st, 1999 to January 31st, 2002

\begin{tabular}{|c|c|c|c|}
\hline Variable & Traditional & 17 steps & $\mathbf{p}$ \\
\hline $\begin{array}{l}\text { Maternal age } \\
\left(\text { mean } \pm S D^{*}\right)\end{array}$ & $25.1 \pm 6.9$ & $23.5 \pm 5.5$ & 0.118 \\
\hline \multicolumn{2}{|l|}{ Number of pregnancies } & & 0.412 \\
\hline 1 & $25(37.3)$ & $37(46.3)$ & \\
\hline 2 & $22(32.8)$ & $19(23.7)$ & \\
\hline 3 or more & $20(29.9)$ & $24(30.0)$ & \\
\hline \multicolumn{2}{|l|}{ Number of deliveries } & & 0.658 \\
\hline 1 & $27(40.3)$ & $38(47.5)$ & \\
\hline 2 & $24(35.8)$ & $24(30.0)$ & \\
\hline 3 or more & $16(23.9)$ & $18(22.5)$ & \\
\hline \multicolumn{2}{|l|}{ Literate } & & 0.382 \\
\hline Yes & $60(89.6)$ & $75(93.8)$ & \\
\hline No & $7(10.4)$ & $5(6.2)$ & \\
\hline \multicolumn{2}{|c|}{ Number of prenatal visits } & & 0.241 \\
\hline $0-3$ & $6(9.0)$ & $3(3.8)$ & \\
\hline $4-6$ & $11(16.4)$ & $20(26.2)$ & \\
\hline$>6$ & $50(74.6)$ & $57(71.2)$ & \\
\hline \multicolumn{4}{|l|}{ child's breastfeeding } \\
\hline Birth weight (grams) & $3,048.7 \pm 480.7$ & $3,026.9 \pm 528.1$ & 0.795 \\
\hline \multicolumn{2}{|l|}{ Sex } & & 0.250 \\
\hline Masculino & $27(40.3)$ & $40(50.0)$ & \\
\hline Feminino & $40(59.7)$ & $40(50.0)$ & \\
\hline $\begin{array}{l}\text { Weeks of pregnancy } \\
(\text { mean } \pm S D)\end{array}$ & $39.2 \pm 1.5$ & $38.4 \pm 2.4$ & 0.021 \\
\hline \multicolumn{2}{|l|}{ Type of delivery } & & 0.810 \\
\hline Vaginal & $48(71.6)$ & $52(65.0)$ & \\
\hline Cesarean & $19(28.4)$ & $28(35.0)$ & \\
\hline \multicolumn{2}{|l|}{ Rooming-in } & & 0.849 \\
\hline Yes & $17(25.4)$ & $19(23.8)$ & \\
\hline No & $50(74.6)$ & $61(76.2)$ & \\
\hline \multicolumn{2}{|l|}{ Paternal cohabitation } & & 0.682 \\
\hline Yes & $52(77.6)$ & $65(81.3)$ & \\
\hline No & $15(25.4)$ & $15(18.7)$ & \\
\hline \multicolumn{4}{|l|}{ 1st feeding } \\
\hline \multicolumn{2}{|l|}{ at delivery room } & & 0.100 \\
\hline Yes & $18(26.9)$ & $12(15.0)$ & \\
\hline No & $49(73.1)$ & $68(85.0)$ & \\
\hline \multicolumn{2}{|l|}{ Help in the 1st feeding } & & 0.219 \\
\hline Yes & $25(37.3)$ & $22(27.5)$ & \\
\hline No & $42(62.7)$ & $58(72.5)$ & \\
\hline \multicolumn{2}{|l|}{ Prenatal guidance } & & 0.281 \\
\hline Yes & $43(64.2)$ & 70 (72.9) & \\
\hline No & $24(35.8)$ & $26(27.1)$ & \\
\hline
\end{tabular}

* $\mathrm{SD}=$ standard deviation.

survival curve is constantly higher than the curve for the traditional group, demonstrating that at all ages the proportion of breastfed children is greater in the "17 steps" group than in the traditional group. Comparing the curves with the log-rank test indicates that there is no significant difference between them $(p=0.057)$. The median breastfeeding duration in the traditional group was 11.5 months. It was not possible to calculate the median for the "17 steps" group because more than $50 \%$ of observations went beyond the cut off.

The low probability of significance, while not significant, indicates a need to consider evaluating the treatment with a regression model. This is because, while the groups were equivalent in terms of the co-variables measured, if the treatment was effective, losses would have occurred in a different manner in each group and the initial composition would not be maintained throughout the process and it is important that this is controlled by a regression model. Table 3 presents the adjusted model.

The following variables were not taken into account in the model: duration of breastfeeding achieved with previous children because there was only information on 91 women who had had other children, type of residence, type of sanitation and indications of the ability to read because of the great homogeneity of the groups in terms of these variables. Because the relationship between mothers' ages and the point at which weaning occurred was non- linear a decision was taken to categorize this variable. This decision was taken for statistical and substantial reasons. Including the co-variable in this manner leads to the best adjustment and to interpretative gains. Maternal age was split into $<20$ years; 20 to 29 years, and 30 years or more. The two last categories did not exhibit significant differences and were joined into a single category, taken as the reference category.

Once adjusted for mother and child characteristics, it was observed that the " 17 steps" group exhibited a reduced risk for weaning between 2 and 12 months compared with the control ( $R R=0.54 ; C I 95 \%=0.30$ to 0.99 ).

Two co-variables exhibited a significant effect: prenatal guidance and the "17 steps" program. The co-variable indicating prenatal guidance presented an association with increased risk of weaning between 2 and 12 months after adjustment for the remaining co-variables ( $R R=2.20$ ), although in the opposite direction to that expected. The effect of the "17 steps" is in the expected direction, with women in the traditional group presented an increased risk of weaning.

Although non-significant, the indicator for adolescent mothers presented a small $p$-value $(p=0.084)$ and a wide confidence interval $(0.92 ; 3.66)$, indicating that there may be a difference between adolescent mothers and adult mothers in terms of breastfeeding duration. Adolescent mother tended to breastfeed for shorter period - higher risk of weaning.

\section{Discussion}

In terms of the characteristics of mothers, children, pregnancy, labor and postpartum there were no significant differences between the traditional and "17 steps" groups.

If children in group 1 were weaned before $1 / 12 / 00$, the date on which the "17 steps" program was initiated, then they only passed through the traditional intervention program. If breastfeeding continued beyond this date then children also benefited from the "17 steps". 


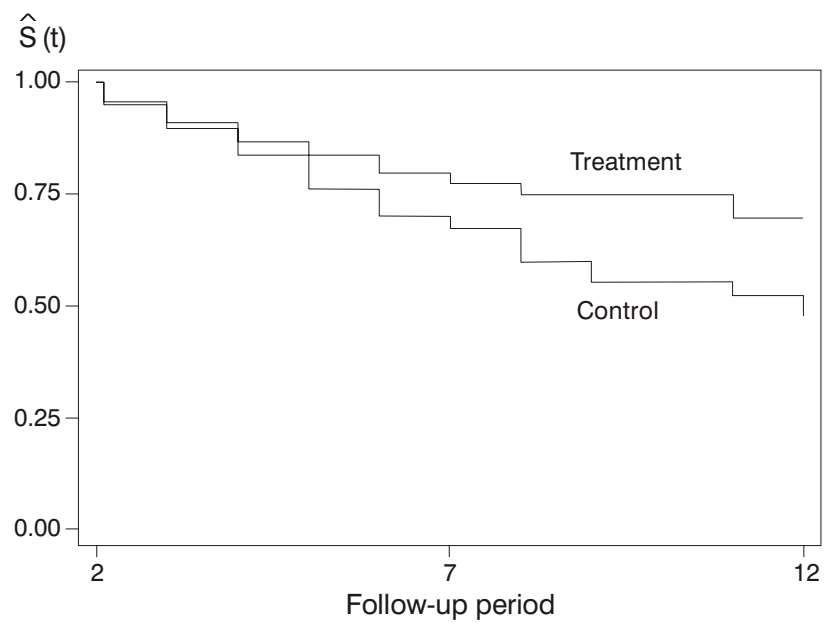

Figure 1 - Percentage of children being breastfed during 10 months in the traditional group and in the " 17 steps" group

All of the strategies for lengthening breastfeeding duration were implanted at the same time, making it impossible to isolate their individual effects. It is possible that a synergic interaction between the strategies may have contributed to the results obtained.

The "17 steps" program has probably contributed to the level of breastfeeding knowledge of health workers, expectant mothers, nursing mothers and the community in general, to encouraging teamwork between health workers and between health workers and the community and to increase community participation in the promotion, support and protection of breastfeeding. It has met steps 3 and 10 of the Baby Friendly Hospital Initiative: "Inform all pregnant women about the benefits and management of breastfeeding" and "Foster the establishment of breastfeeding support groups and refer mothers to them on discharge from the hospital or birthing center", respectively. It has humanized mother-

Table 3 - Analysis of the Cox regression model after the adjustment taking into consideration all co-variables of the questionnaire that presented an adequate number of cases

\begin{tabular}{|c|c|c|c|}
\hline Variable & $\mathbf{R R} *$ & $95 \% \mathrm{CI}^{\dagger}$ & $\mathbf{p}$ \\
\hline Male $\mathrm{NB}^{\ddagger}$ & 1.01 & $0.52-1.96$ & 0.708 \\
\hline Adolescent mother & 1.84 & $0.92-3.66$ & 0.084 \\
\hline Rooming-in & 1.11 & $0.58-2.13$ & 0.751 \\
\hline First pregnancy & 0.68 & $0.34-1.38$ & 0.291 \\
\hline Father's presence & 0.74 & $0.36-1.51$ & 0.404 \\
\hline 0-3 PN§ visits & 0.95 & $0.28-3.19$ & 0.930 \\
\hline 4-6 PN visits & 0.94 & $0.43-2.05$ & 0.876 \\
\hline PN guidance & 2.20 & $1.07-4.50$ & 0.031 \\
\hline Vaginal delivery & 1.32 & $0.68-2.55$ & 0.414 \\
\hline 17 steps progam & 0.54 & $0.30-0.99$ & 0.047 \\
\hline $\begin{array}{l}* \mathrm{RR}=\text { relative risk. } \\
\neq \mathrm{NB}=\text { newborn. }\end{array}$ & $\begin{array}{ll}\dagger & \mathrm{Cl} \\
\S & \mathrm{PN}\end{array}$ & $\begin{array}{l}\text { dence interv } \\
\text { natal }\end{array}$ & \\
\hline
\end{tabular}

child care, made the Health Center into a breastfeeding problems emergency room and, most possibly, could make the health center a center of excellence in the area of breastfeeding and a training center for multidisciplinary breastfeeding teams.

Step 4 - the expectant mother has a consultation with a pediatrician just before birth - was not implemented, but we thought that it would be important to, a few days before going into hospital, to reflect with the mother on the first suckle in the delivery room, on rooming-in, on feeding on demand, on let down and on exclusive breastfeeding without pacifiers. With respect of step 8 , there were no transgressions within the health center.

Traditional care may vary and results may not be so significant with a population that is already receiving more effective traditional care than was offered by the São Francisco Health Center. Populations receiving worse traditional treatment may show even more favorable results. This study demonstrates that simple strategies, within the reach of any health center, are effective at increasing breastfeeding duration.

Children in the traditional group who were still breastfeeding at the time the program was implemented benefited from it in terms of homage paid to mothers, pediatric care even without space in the appointments book, from the lending of reading material to take home, from monthly or bimonthly follow-up appointments and from the training and sensitization of professionals. This may have increased the duration of breastfeeding for some of the group 1 children, thus underestimating the impact of the program, under evaluation.

Attention was also paid to the possibility that mothers might say they were breastfeeding when they were not thinking that this would please the interviewer, taking into account the obvious value given to breastfeeding at the São Francisco Health Center and the pediatric care even without appointments for breastfed children. In an attempt to avoid this bias, mothers were asked what type of foods the child was receiving at that point, not if the child was being breastfed or not, always being alert for signs that artificial milk was being used such as mothers carrying feeding bottles, children becoming ill with frequency and altered fecal odor. In cases of doubt mothers were observed breastfeeding, thus avoiding this classification bias.

The researcher knew which children had passed through the traditional program and which had followed the "17 steps", creating a possibility that this could constitute observer bias. All care was taken to ensure that one group did not benefit to the detriment of the other.

Encouraging breastfeeding is very important, but the emotional and technical support that should be offered at childcare follow-up consultations must not be forgotten. Many children who are weaned early have mothers who want to and can breastfeed. Mothers who want breastfeed and can't suffer great frustration. Encouraging breastfeeding without providing conditions for it to be achieved can cause mothers who are impotent to remove these obstacles in the path of breastfeeding to feel guilty. 
The "Breastfeeding Friendly Basic Health Unit" (BFBHU) initiative, given official approval by the Health Ministry in 2003, is fundamentally based on the capacitation of professionals and on advising expectant and nursing mothers on procedures that research has shown increase breastfeeding duration. Basic health unit infrastructure evaluations and interviews with prenatal and pediatric professionals and with mothers result in global scores from one (all steps completely fulfilled by the unit) to zero (inadequate infrastructure and none of the procedures put into practice with pregnant women or mothers). Research at 24 health units found an AME duration expectancy of 1.6 months for babies less than 6 months old cared for at units whose performance is listed as normal (global score over 0.33 ) and at 1.1 months for babies cared for at units with performance rated as poor (global score less than or equal to 0.33$).{ }^{23}$ The "17 steps" program was initially named "Baby Friendly Basic Health Unit Initiative", ${ }^{24}$ and was renamed in order to avoid confusion with the BFBHU. This was basically founded on support strategies used to make sure that information, guidance and procedures reach mothers, to avoid problems occurring and solve any that do. It increased by $85 \%$ the chances of children breastfeeding at 2 months still doing so at 1 year, leading to predictions that a combination of these two programs would extend even further breastfeeding duration.

\section{References}

1. OMS/UNICEF. Reunion conjunta OMS/UNICEF sobre la alimentacion del lactante y del niño pequeño. Genebra: OMS; 1979.

2. Araújo LDS. Querer/poder amamentar: uma questão de representação? [tese] Londrina: Universidade Estadual de Londrina; 1997.

3. BEMFAM. Sociedade Civil Bem-Estar Familiar no Brasil. Pesquisa nacional sobre demografia e saúde. 1996. Amamentação e situação nutricional das mães e crianças. Rio de Janeiro: 1997;125-38.

4. Sokol EJ. Em defesa da amamentação: manual para implementar o Código Internacional de Mercadização de Substitutos do Leite Materno. São Paulo: IBFAN Brasil; 1999.

5. Cavalcanti MLF. Conhecimentos, atitudes e práticas do pessoal de saúde sobre aleitamento materno [tese]. São Paulo: Universidade de São Paulo; 1982.

6. Souza LMBM. Promoção, proteção e apoio. Apoio? Representações sociais em aleitamento materno [dissertação] Rio de Janeiro: IFF/FIOCRUZ; 1996.

7. Neylor A, Wester R. Providing professional lactation management consultation. Clin Perinatol. 1987;14:33-50.
8. Valdés V, Pérez A, Labbok M, Pugin E, Zambranco I, Catalan S. The impact of a hospital and clinic-based breastfeeding promotion programme in a middle class urban environment. J Trop Pediatr. 1993;39:142-51.

9. Kleinbaum DG, Kupper LL, Margenstein H. Epidemiologic Research: principles and quantitative methods. New York: Van Nostrand Reinhold; 1982.

10. Popkin BM. An evaluation of a national breastfeeding promotion programme in Honguras. J Biosoc Sci. 1991;23:5-21.

11. Rossiter JC. The effect of a culture-specific education program to promote breastfeeding among Vietnamese women in Sydney. Int J Nurs Studies. 1994;31:369-79.

12. Arora S. Major factors influencing breastfeeding rates: mother's perception of father's attitude and milk supply. Pediatrics. 2000;106:1-5.

13. Correa AMS. Evaluacion del impacto de las atividades de promocion de la lactancia materna. Hospital Guilherme Álvaro. USAID/LAC; fev/1994.

14. Valdés V, Sánchez AP, Labbok M. Manejo clínico da lactação. Assistência à nutriz e ao lactente. Rio de Janeiro: Revinter; 1996.

15. Valdés $V$, Schooley $\mathrm{J}$. The role of education in breastfeeding success. Food and Nutr Bull. 1991;12:431-9.

16. Moura EFA. Duração do período do aleitamento materno de crianças atendidas em ambulatório de pediatria. J Pediatr (Rio J). 1997:73:106-10.

17. Grossman LK, Harter C, Hasbrouck C. Testing mother's knowledge of breastfeeding: instrument development and implementation and correlation with infant feeding decision. J Pediatr Perinatol Nutr. 1990;1:43-63.

18. OMS/UNICEF. Aconselhamento em amamentação: um curso de treinamento. Guia do Treinador; 1993.

19. Susin LRO, Giugliane ERJ, Krumer SC, Maciel M, Benjamin ACW, Baêta $M$, et al. Uma estratégia simples que aumenta os conhecimentos das mães em aleitamento materno e melhora as taxas de amamentação. J Pediatr (Rio J). 1998;74:368-75.

20. Alvarado R. Evaluation of a breastfeeding-support programme with health promoters' participation. Food and Nutr Bull. 1996; 17:49-53.

21. WHO. Indicators for assessing breastfeeding practices. Geneva; 1991.

22. Dean AG, Dean JA, Coulombier D, Brendel KA, Smith DC, Burton $\mathrm{AH}$, et al. Epi Info, version 6: a Word Processing, Database, and Statistics Program for Epidemiology on Microcomputers. Centers of Disease Control and Prevention. Atlanta, Georgia; 1994.

23. Oliveira MIC, Camacho LAB. Impacto das Unidades Básicas de Saúde na duração do aleitamento materno exclusivo. Rev Bras Epidemiol. 2002;5(1):41-51.

24. Lana APB. O livro de estímulo à amamentação: uma visão biológica, fisiológica e psicológica-comportamental da amamentação. Belo Horizonte: Atheneu; 2001.

Corresponding author:

Adolfo Paulo Bicalho Lana

Rua Pio Porto Menezes, 120/104A

CEP 30380-300 - Belo Horizonte, MG, Brazil

Tel.: +55 (31) 9973.2717

Fax: +55 (31) 3337.8836

E-mail: adolfobicalholana@bol.com.br 